\title{
IN HOUD.
}

$\mathrm{Blz}$.

Naamlijst der leden van het Instituut

Lijst der binnen- en buitenlandsche academiën, geleerde genootschappen en instellingen, waarmede het Koninklijk Instituut door ruiling der uitgegeven werken in verbinding is . . . . . . . . . . . XIv 237 ste Bestuursvergadering, 20 Januari 1883 . . . XvII $238^{\text {ste }}$ Bestuursvergadering, 17 Februari 1883. . . . $\mathrm{xx}$ $239^{\text {ste }}$ Bestuursvergadering, 17 Maart $18 \$ 3$. . . . XXv Algemeene Vergadering, 24 Februari 1883 . . . . $\quad$ xxxI Verslag van den staat en de werkzaamheden van het Instituut over 1882 . . . . . . . . . . . . xxxvIII Dagboek van Dr. H. A. Bernstein's laatste reis van Ternate naar Nieuw-Guinea, Salawati en Batanta, 17 October 1864-19 April 1865, bewerkt door Mr. S. C. J. W. van Musschenbroek. Met aanteekeningen, bijlagen en eene kaart . . . . . . . .

Naar aanleiding van Dr. C. Snouck Hurgronje's „Nieuwe bijdragen tot de kennis van den Islam" door Dr. A. W. T. Juynboll . . . . . . . . . . . . 259 


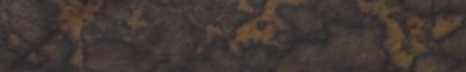

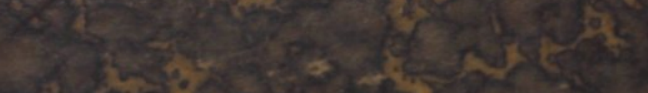

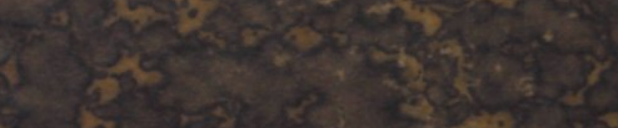

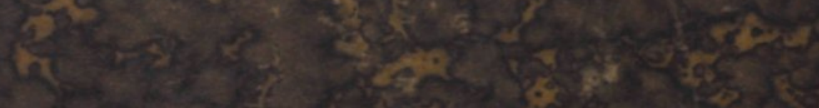

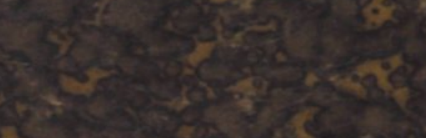

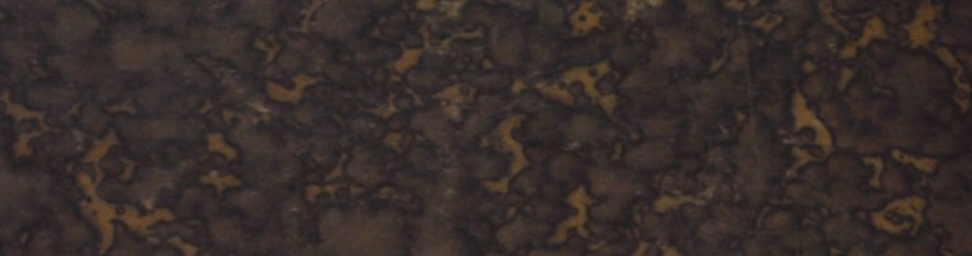

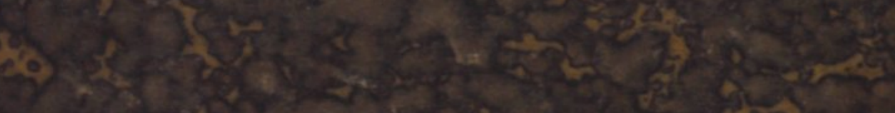

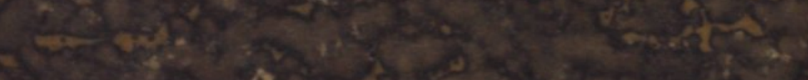

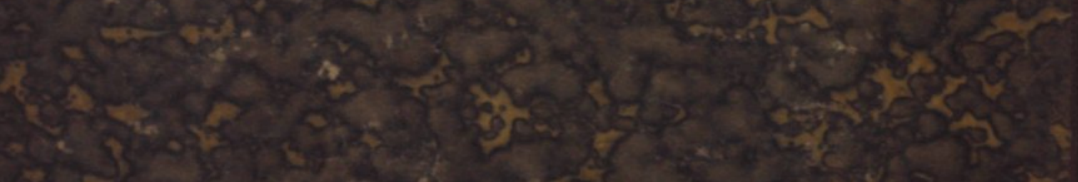

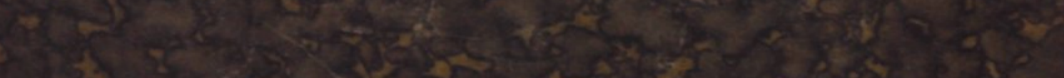

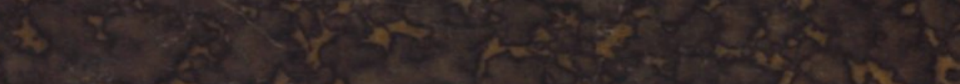

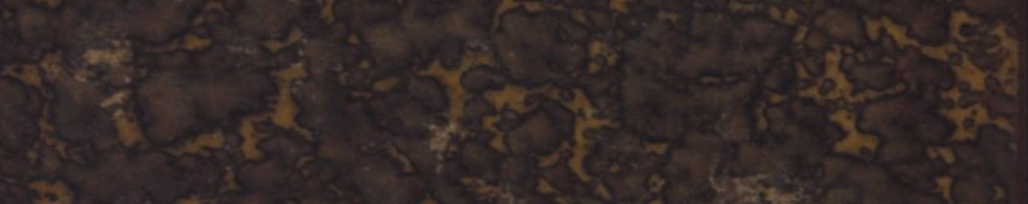

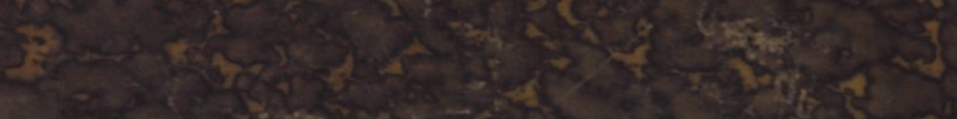
23

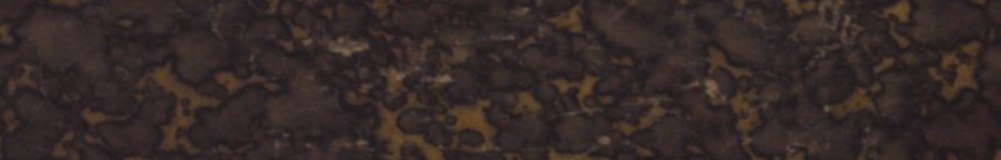

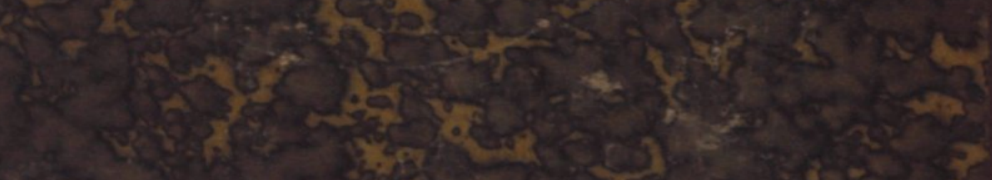

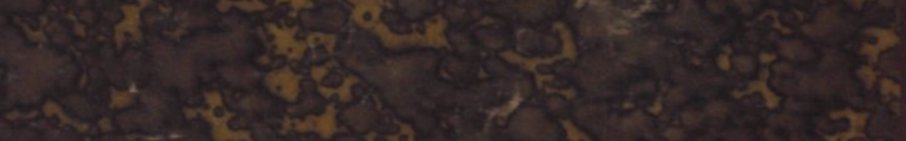

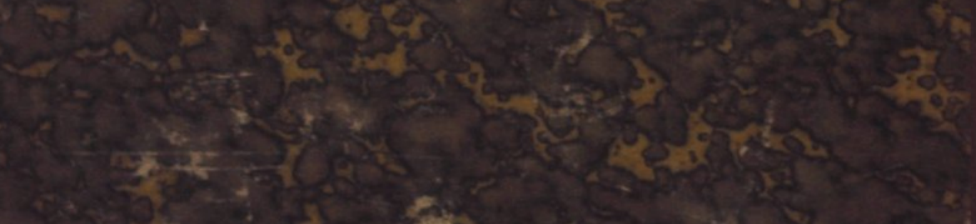

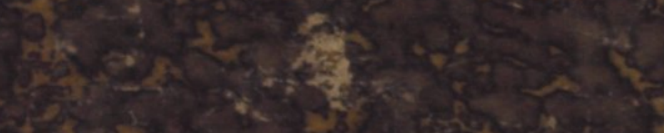

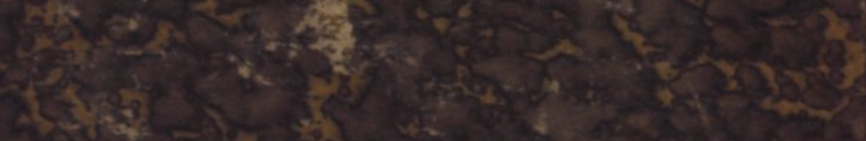

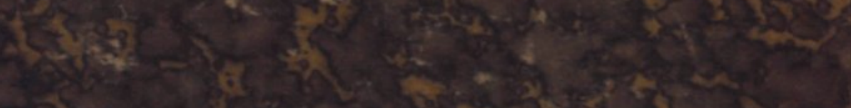

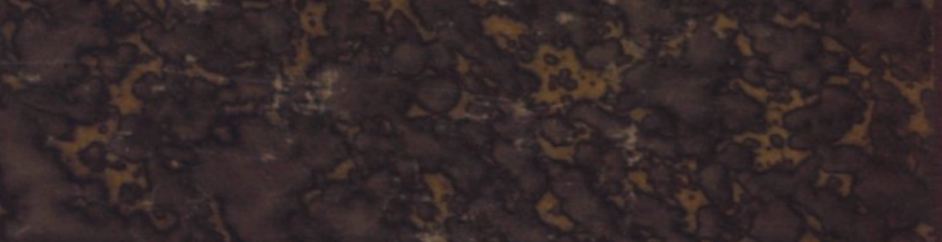
2

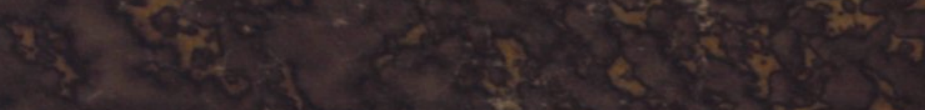

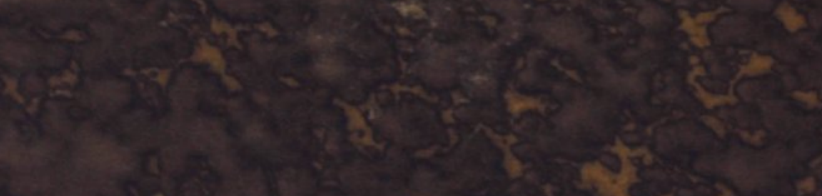

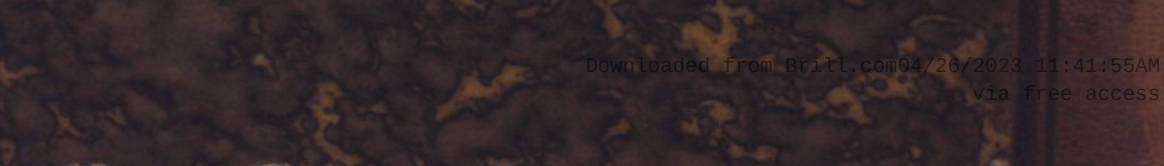

